Research Article

\title{
Comparisons between Asphalt Pavement Responses under Vehicular Loading and FWD Loading
}

\author{
Song Yang, ${ }^{1}$ Bing Qi, ${ }^{1}$ Zhensheng Cao, ${ }^{1}$ Shaoqiang Zhang, ${ }^{1}$ Huailei Cheng $\left(D,{ }^{2,3}\right.$ \\ and Ruikang Yang ${ }^{2}$ \\ ${ }^{1}$ Powerchina Roadbridge Group Co., Ltd., Beijing, China \\ ${ }^{2}$ The Key Laboratory of Road and Traffic Engineering of the Ministry of Education, Tongji University, Shanghai, China \\ ${ }^{3}$ Department of Civil and Environmental Engineering, The Hong Kong Polytechnic University, Hong Kong, China
}

Correspondence should be addressed to Huailei Cheng; chl6218@126.com

Received 12 August 2020; Revised 16 October 2020; Accepted 19 October 2020; Published 29 October 2020

Academic Editor: Yuqing Zhang

Copyright (c) 2020 Song Yang et al. This is an open access article distributed under the Creative Commons Attribution License, which permits unrestricted use, distribution, and reproduction in any medium, provided the original work is properly cited.

The strain responses of asphalt pavement layer under vehicular loading are different from those under falling weight deflectometer (FWD) loading, due to the discrepancies between the two types of loadings. This research aims to evaluate and compare the asphalt layer responses under vehicular loading and FWD loadings. Two full-scale asphalt pavement structures, namely, flexible pavement and semirigid pavement, were constructed and instrumented with strain gauges. The strain responses of asphalt layers under vehicular and FWD loadings were measured and analyzed. Except for field measurements, the finite element (FE) models of the experimental pavements were established to simulate the pavement responses under a wide range of loading conditions. Field strain measurements indicate that the asphalt layer strain under vehicular loading increases with the rising temperature roughly in an exponential mode, while it decreases with the rising vehicular speed approximately linearly. The strain pulses in the asphalt layer generated by FWD loading are different from those induced by vehicular loading. The asphalt layer strains generated by FWD loading are close to those induced by low vehicular speed $(35 \mathrm{~km} / \mathrm{h})$. The results from the FE model imply that the asphalt layer strains under FWD loading and vehicular loading are distributed similarly in the depth profile. For flexible pavement, the position of critical strain shifts gradually from the bottom of the asphalt layer to the mid-depth of the layer, as the temperature increases. For semirigid pavement, the position of critical strain is always located at the intermediate depth of the asphalt layer, regardless of temperatures.

\section{Introduction}

Asphalt pavement constitutes one of the most common pavement structures for highways or steel bridge roadways. To design high-performance asphalt pavement, various methods have been elaborated worldwide to guide asphalt pavement design [1-5]. One frequently used asphalt pavement design method is the mechanistic-empirical (ME) method. In the ME method, the strain response of the asphalt layer is one essential parameter $[1,6]$. The strain response is used to estimate pavement performance and control pavement design results $[5,7]$. Considering that vehicular loading is the most common loading on the pavement, the strain responses of the asphalt layer under this type of loading are utilized in the design method.

The falling weight deflectometer (FWD) loading test is widely used to assess the in situ pavement condition in a rapid and nondestructive way [8-13]. In pavement overlay design or rehabilitation design, the FWD test results are applied to obtain the in situ moduli of existing pavement layers [6]. The obtained in situ moduli are used to predict the responses and the remaining fatigue life of the in situ pavement under repeated vehicular loadings [6]. Therefore, it is assumed that the properties of the asphalt layer measured based on FWD test reflect what asphalt layer exhibits under actual vehicular loading. However, considerable differences exist between vehicular loading and FWD 
loading. On the one hand, the loading time of FWD varies from $0.028 \mathrm{~s}$ to $0.030 \mathrm{~s}$, while that of vehicular loading is

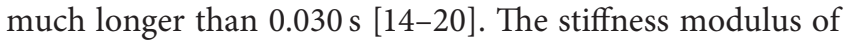
asphalt mixture is dependent on loading time [21-23]. Therefore, the asphalt mixture modulus induced by FWD loading can be different from that induced by vehicular loading. On the other hand, the FWD loading is impact loading, while the vehicular loading is moving load caused by rolling tires. Besides, the shapes of loading contact areas of FWD loading and vehicular loading are also different. Due to the discrepancies in loading time, loading pattern (impact vs. rolling) and loading contact area, the asphalt layer responses under vehicular loading and FWD loading tend to behave diversely. To better apply FWD data in pavement evaluation or pavement design, it is necessary to identify the relationship between pavement responses under FWD loading and vehicular loading.

Several studies have been conducted to correlate asphalt layer responses under FWD and vehicular loadings. Mateos and Snyder [24] compared the strain responses of Minnesota test road under FWD and vehicular loadings and found that the strains of asphalt layer under FWD loading resemble those under vehicular loading with speed at $48 \mathrm{~km} / \mathrm{h}$. Therefore, they concluded that the FWD loading represents the vehicular speed at $48 \mathrm{~km} / \mathrm{h}$. Based on a similar concept and method, Qin [25] reported that FWD loading reflects vehicular loading at approximately $88 \mathrm{~km} / \mathrm{h}$. Ai et al. [26] reported that the equivalent speeds of the FWD loading range between 26 and $48 \mathrm{~km} / \mathrm{h}$. Wang and Li [27] calculated the theoretical pavement responses under FWD loading and vehicular loading via the finite element method and found that the FWD loading corresponds to vehicular speeds ranging between 24 and $80 \mathrm{~km} / \mathrm{h}$. As can be seen, the equivalent speeds of FWD loading in previous studies vary greatly from $24 \mathrm{~km} / \mathrm{h}$ to $88 \mathrm{~km} / \mathrm{h}$. Hence, more research is still needed further to determine the proper scope of equivalent speeds for FWD loading.

This research aimed to further investigate and compare the asphalt layer responses under vehicular and FWD loadings. Two full-scale asphalt pavement structures, namely, flexible pavement and semirigid pavement, were constructed and instrumented with strain gauges. The strain responses of field asphalt layers under vehicular and FWD loadings were measured. Based on strain measurements, the effects of temperature, vehicular speed, and axle load on asphalt layer strains were analyzed. The equivalent vehicular speed of FWD loading was determined using the criterion that the maximum tensile strains in the asphalt layer induced by FWD and vehicular loadings were equal. Except for field measurements, the finite element (FE) models of the experimental pavements were established to simulate the pavement responses under a wider range of loading conditions. The calculation results from FE model were used to analyze the position of critical strains in the flexible and semirigid pavement.

\section{Field Strain Measurements}

2.1. Pavement Structures and Materials. Two full-scale experimental pavements, namely, flexible and semirigid pavements, were built to measure strain responses of asphalt layers. The pavement structures are shown in Figure 1. The design of two pavements follows the specification JTG D50 [28].

As presented in Figure 1, the flexible and semirigid pavements have the same asphalt layer (AC-13 mixture layer), subbase layer (graded gravel), and subgrade. The difference between the two pavements lies in the base layer. The semirigid pavement uses the cement-stabilized macadam as the base layer, while the flexible one uses the graded gravel. The thicknesses of the asphalt layer, base layer, and subbase layer in the pavement are $30 \mathrm{~cm}, 35 \mathrm{~cm}$, and $20 \mathrm{~cm}$, respectively. The AC-13 asphalt mixture layer uses the neat asphalt binder having the penetration grade at 60/70. The design process of the AC-13 mixture is in accordance with the specification JTG F40 [29], ensuring that the output AC$13 \mathrm{mix}$ meets all performance requirements. The Marshall properties and the aggregate gradation of the designed AC13 mixture are presented in Table 1 and Figure 2, respectively.

2.2. Field Tests. Asphalt strain gauges (Tokyo Sokki KMS100) were installed in field asphalt layers to measure its strain responses. The reliability of this type of gauge has been proven in previous research projects, including the MnROAD project and the RIOHT project [30-32]. As shown in Figure 1, for flexible pavement, strain gauges are installed at two depths, namely, $6 \mathrm{~cm}$ and $30 \mathrm{~cm}$. For semirigid pavement, the gauges are settled at two depths of $13 \mathrm{~cm}$ and $24 \mathrm{~cm}$. Each depth consists of four strain gauges, of which two are oriented to measure longitudinal strains, while the remaining two are used to measure transverse strains. The diagrams of strain gauge and field installation of the gauge are presented in Figure 3.

Field tests are conducted to measure the strain responses of asphalt layers based on the full-scale experimental pavements. Both vehicular loading and FWD loading are included in field tests. The vehicular loading is applied using one large-scale accelerated pavement testing (APT) facility named MLS 66. The MLS 66, which is manufactured by the South African company PaveTesting, can accurately control the speed, the axle load, and the wheel path of the vehicular loading. The MLS 66 is equipped with a single axle with dualtire wheels. During the test, one tire of MLS 66 is designed just to pass over the strain gauges. FWD loading is applied by an FWD facility produced by Sweco Danmark A/S company. In the field test, the loading plate of FWD is placed right above the strain gauge. The photographs of vehicular and FWD loading tests are presented in Figure 4.

Different magnitudes of asphalt layer temperatures, vehicular speeds and axle loads are included in field tests to evaluate the strain responses of asphalt layer under various temperature and loading conditions. The exact temperature and loading conditions in vehicular loading tests are summarized in Table 2. The FWD loading tests consist of three pavement temperatures at $15^{\circ} \mathrm{C}, 25^{\circ} \mathrm{C}$, and $35^{\circ} \mathrm{C}$. The magnitude of the falling weight in FWD tests stays constant at $50 \mathrm{kN}$. 


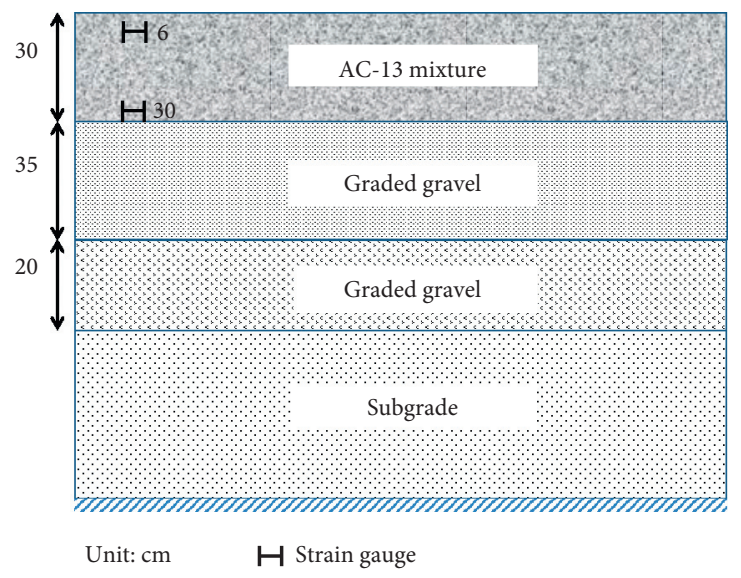

(a)

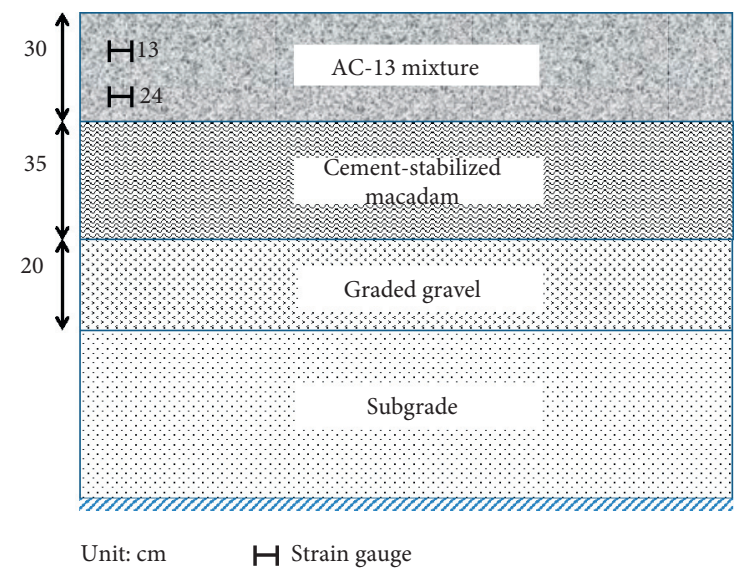

(b)

Figure 1: The structures of (a) flexible pavement and (b) semirigid pavement.

TABLE 1: The Marshall properties of the AC-13 mixture.

\begin{tabular}{lc}
\hline Properties & Value \\
\hline Asphalt content $(\%)$ & 5.1 \\
Density $\left(\mathrm{g} / \mathrm{cm}^{3}\right)$ & 2.432 \\
Air voids $(\%)$ & 3.3 \\
VMA $(\%)$ & 14.7 \\
VFA $(\%)$ & 77.6 \\
Marshall stability $(\mathrm{kN})$ & 10.6 \\
\hline
\end{tabular}

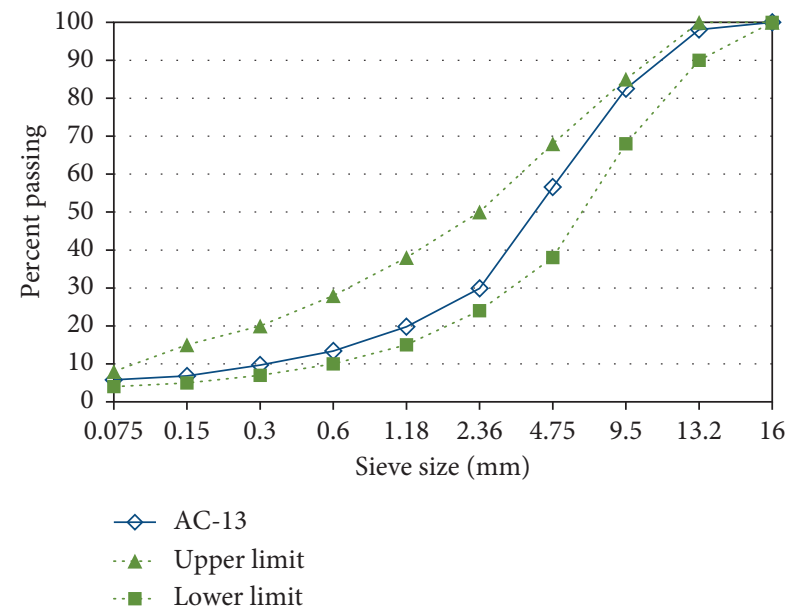

Figure 2: The aggregate gradation of the AC-13 mixture.

\section{Strain Measurements Analysis}

3.1. Measured Strain Pulses of Asphalt Layer under Vehicular Loading. The strain pulses of asphalt layer under vehicular loading are measured from field tests. It is found that strain pulse within the asphalt layer of semirigid pavement has a similar shape for different temperature and loading conditions. The typical transverse and longitudinal strain pulses of semirigid pavement are presented in Figure 5.

As shown in Figure 5, the transverse strain pulse mainly contains tensile strain zone, while the longitudinal one contains both tensile and compressive strain zones. The magnitude of compressive strain in the longitudinal pulse is lower than that of tensile strain, with the former value approximately half of the latter one. The maximum tensile strain of longitudinal pulse exceeds that of transverse pulse, indicating that the asphalt layer is more likely to suffer fatigue damage in the longitudinal direction. Both transverse and longitudinal pulses are asymmetric, which is mainly caused by the viscoelastic property of the asphalt mixture. In addition, the tensile strain of the asphalt layer at $13 \mathrm{~cm}$ is always larger than that at $24 \mathrm{~cm}$, regardless of temperature and loading conditions. This fact implies that the critical position of fatigue damage in the semirigid pavement is roughly located in the middle of the asphalt layer.

For the flexible pavement, the strain pulses at the bottom of the asphalt layer $(30 \mathrm{~cm})$ are similar to the pulses presented in Figure 6. The strain pulses at $6 \mathrm{~cm}$ of the asphalt layer, however, have different shapes when the pavement temperature varies. Figure 6 shows the typical strain pulses at $6 \mathrm{~cm}$ of asphalt layer under intermediate and high temperatures.

At intermediate temperatures $\left(\leq 25^{\circ} \mathrm{C}\right)$, both tensile and compressive strains exist in the transverse and longitudinal pulses. The magnitude of tensile strain is basically identical or slightly lower than that of compressive strain. When the pavement temperature rises to outnumber $35^{\circ} \mathrm{C}$, the compressive strain zone in the transverse pulse disappears. By contrast, the tensile strain zones in two pulses turn much more apparent. Similar to the semirigid pavement, the strain pulses within flexible pavement also exhibit asymmetry during the loading of the moving axle.

For flexible pavement, the position of critical tensile strain in the asphalt layer is dependent on temperature. At intermediate temperatures, critical tensile strain appears at the bottom of the asphalt layer. As the temperature increases to be higher $\left(\geq 35^{\circ} \mathrm{C}\right)$, critical tensile strain occurs at a depth of $6 \mathrm{~cm}$, and its value is obviously larger than that corresponding to intermediate temperature. Therefore, the critical position of fatigue damage in flexible pavement varies gradually from the asphalt layer bottom to the layer surface as temperature rises. 


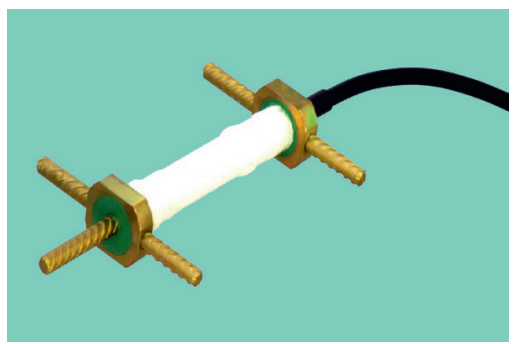

(a)

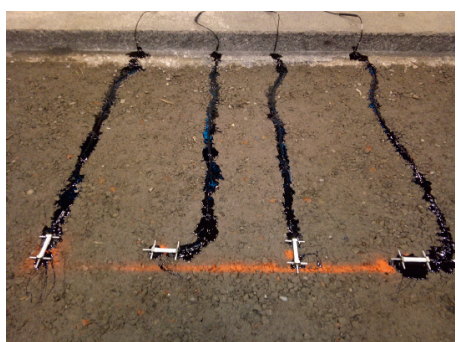

(b)

FIgURE 3: The diagrams of (a) strain gauge and (b) field installation of strain gauges.

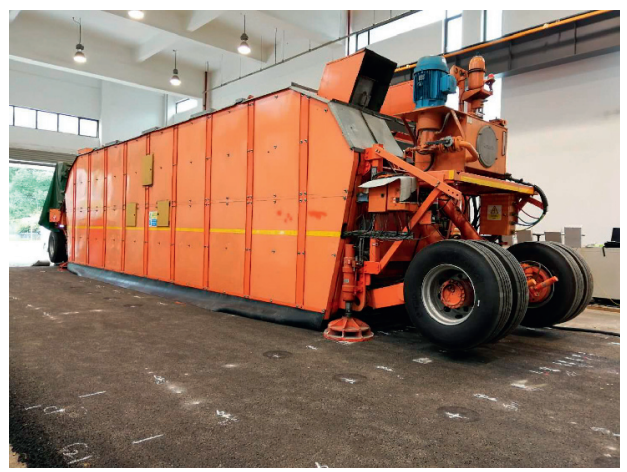

(a)

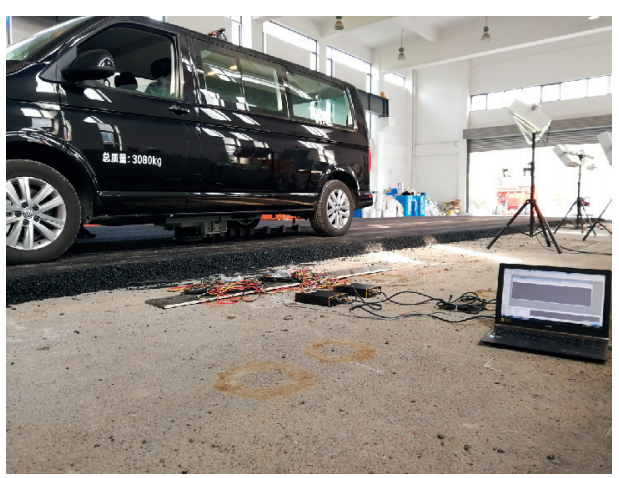

(b)

FIgURE 4: The photographs of (a) vehicular loading test and (b) FWD loading test.

TABLE 2: The loading conditions in vehicular loading tests.

\begin{tabular}{lccc}
\hline $\begin{array}{l}\text { Pavement } \\
\text { type }\end{array}$ & $\begin{array}{c}\text { Temperature } \\
\left({ }^{\circ} \mathrm{C}\right)\end{array}$ & $\begin{array}{c}\text { Vehicular speed } \\
(\mathrm{km} / \mathrm{h})\end{array}$ & $\begin{array}{c}\text { Axle load } \\
(\mathrm{kN})\end{array}$ \\
\hline \multirow{3}{*}{ Semirigid } & 15 & $5.5,11,16.5,22$ & 50 \\
& 25 & $5.5,11,16.5,22$ & $\begin{array}{c}20,35,50, \\
60,75\end{array}$ \\
& 35 & $5.5,11,16.5,22$ & 50 \\
& 45 & $5.5,11,16.5,22$ & 50 \\
\hline \multirow{3}{*}{ Flexible } & 10 & $5.5,11,16.5,22$ & 50 \\
& 15 & $5.5,11,16.5,22$ & 50 \\
& 25 & $5.5,11,16.5,22$ & $20,35,50$, \\
& 35 & $5.5,11,16.5,22$ & 50,75 \\
& 45 & $5.5,11,16.5,22$ & 50 \\
\hline
\end{tabular}

3.2. Measured Strain Pulses of Asphalt Layer under FWD Loading. The typical strain pulses of asphalt layers in two pavements under FWD loading are shown in Figure 7.

As shown in Figure 7, the strain pulses of asphalt layer induced by FWD loading are significantly different from those under vehicular loading. The strain pulses under FWD loading consist of multiple peaks or valleys. Those continuous strain peaks or valleys are caused by the vibration of FWD loading. The first pulse peak (valley) corresponds to the applied falling weight, while the remaining peaks (valleys) are generated by loading vibration. Moreover, the strain pulse under FWD loading lasts only around $0.03 \mathrm{~s}$. In contrast, the duration of strain pulses

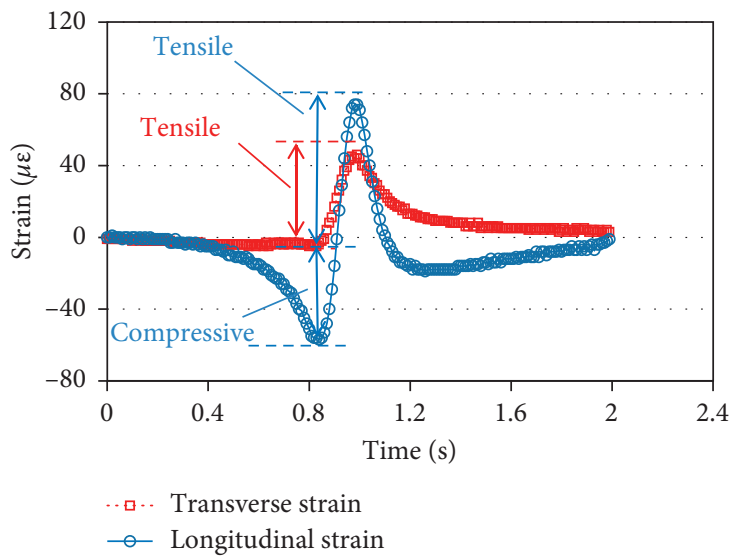

FIgURE 5: The typical transverse and longitudinal strain pulses of semirigid pavement.

caused by vehicular loading noticeably exceeds $0.03 \mathrm{~s}$ (as seen in Figures 6 and 7).

\subsection{Effects of Temperature and Vehicular Speed on Measured} Strain Values. The strain value of the asphalt layer is calculated as the maximum strain response in the strain pulse. Based on the above method, the strain values of the asphalt layer at different temperature and loading conditions are obtained. The effects of temperature and vehicular speed on strain values are analyzed. The exemplary varying trend of 


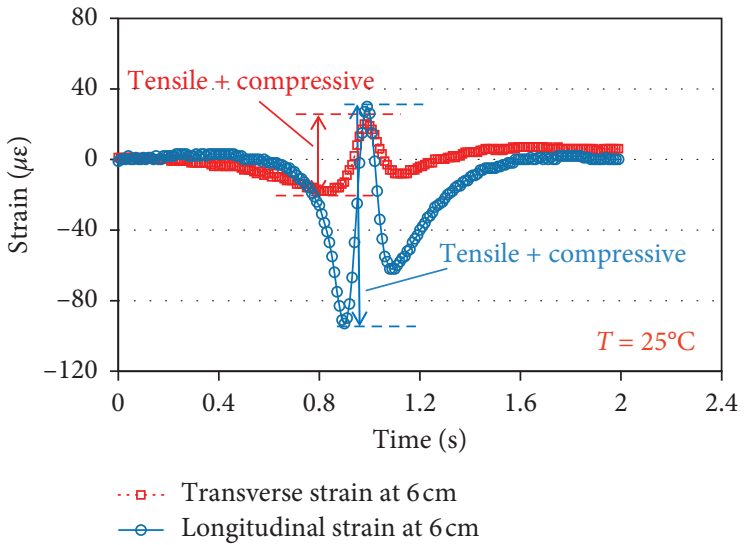

(a)

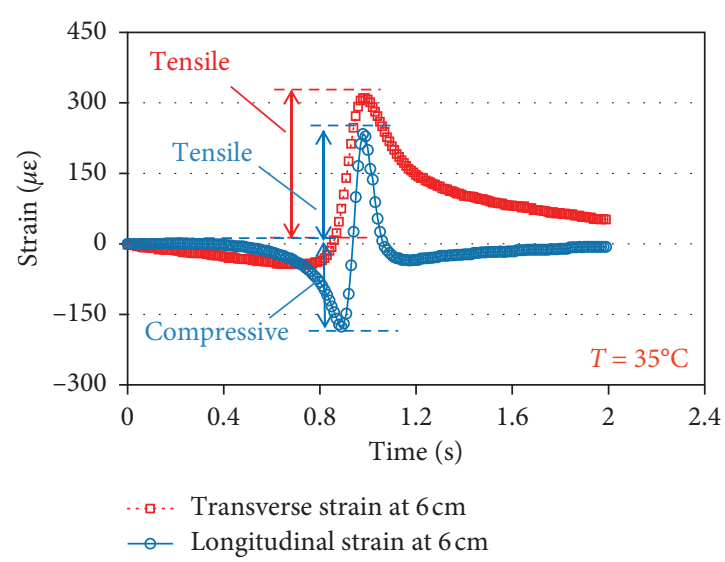

(b)

Figure 6: Typical strain pulses at $6 \mathrm{~cm}$ of asphalt layer under (a) intermediate and (b) high temperatures.

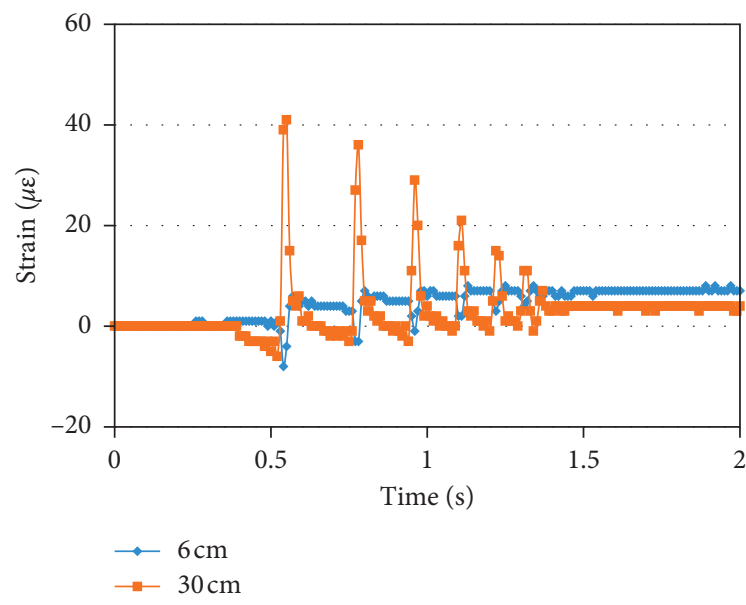

(a)

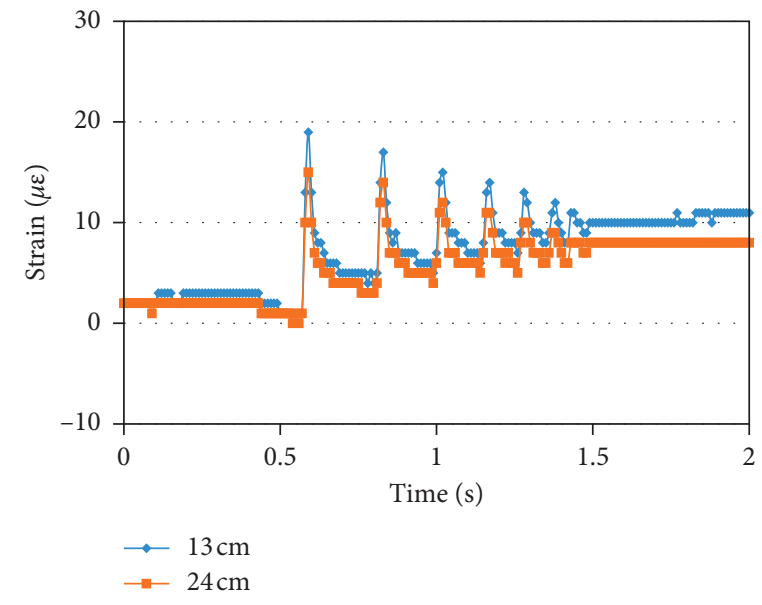

(b)

FIGURE 7: Typical strain pulses of asphalt layer under FWD loading for (a) flexible pavement and (b) semirigid pavement.

strain values with temperature and vehicular speed is presented in Figure 8. In this particular case, the transverse strains of semirigid pavement at a depth of $13 \mathrm{~cm}$ are used.

As shown in Figure 8(a), the strain value of asphalt layer increases with the temperatures roughly in an exponential mode, which implies the viscoelastic properties of asphalt mixture layer. Specifically, the strain values at $45^{\circ} \mathrm{C}$ are nearly 40 times higher than those at $15^{\circ} \mathrm{C}$. Vehicular speed also has a significant effect on the strain value, but its effect is relatively moderate as compared with that of temperature. As shown in Figure 8(b), the strain values decrease approximately linearly with the rising vehicular speed. The decreasing rate of strain value with speed is influenced by temperature. The slopes of strain-speed lines at high temperatures are apparently higher than those at intermediate temperatures. Therefore, the effect of vehicular speed on strain value is more predominant at high-temperature conditions.

The detailed strain values of asphalt layer at different temperature and loading conditions are summarized in Tables 3 and 4.

Based on the data shown in Figure 8 and Tables 5 and 6, the following model is chosen to describe the relationship among strain values, vehicular speed, and temperature:

$$
\varepsilon=\left(a_{1} \cdot V+a_{2}\right) \cdot e^{a_{3} \cdot T},
$$

where $\varepsilon$ is strain value $(\mu \varepsilon), V$ is vehicular speed $(\mathrm{km} / \mathrm{h}), T$ is temperature $\left({ }^{\circ} \mathrm{C}\right)$, and $a_{1}, a_{1}$, and $a_{3}$ refer to model parameters. $a_{1}$ represents the sensitivity of strain value to vehicular speed, while $a_{3}$ represents the sensitivity of strain value to temperature. 


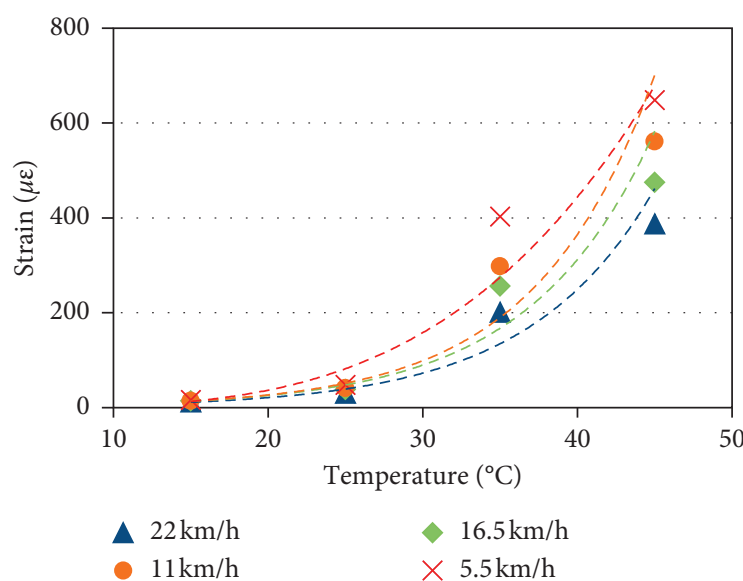

(a)

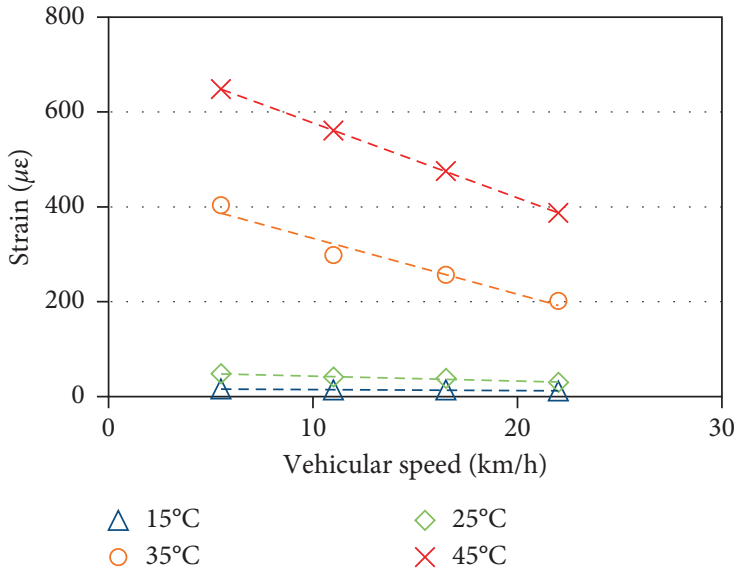

(b)

FIgURE 8: The exemplary varying trend of strain values with (a) temperatures and (b) vehicular speeds.

TABLE 3: Strain values of asphalt layer in the flexible pavement at different conditions.

\begin{tabular}{|c|c|c|c|c|c|}
\hline \multirow{2}{*}{ Temperature $\left({ }^{\circ} \mathrm{C}\right)$} & \multirow{2}{*}{ Speed $(\mathrm{km} / \mathrm{h})$} & \multicolumn{2}{|c|}{$6 \mathrm{~cm}$} & \multicolumn{2}{|c|}{$30 \mathrm{~cm}$} \\
\hline & & Transverse strain $(\mu \varepsilon)$ & Longitudinal strain $(\mu \varepsilon)$ & Transverse strain $(\mu \varepsilon)$ & Longitudinal strain $(\mu \varepsilon)$ \\
\hline \multirow{4}{*}{10} & 22 & 6 & 16 & 16 & 32 \\
\hline & 16.5 & 6 & 18 & 17 & 33 \\
\hline & 11 & 7 & 20 & 18 & 36 \\
\hline & 5.5 & 9 & 23 & 20 & 40 \\
\hline \multirow{4}{*}{15} & 22 & 10 & 26 & 19 & 36 \\
\hline & 16.5 & 11 & 28 & 23 & 42 \\
\hline & 11 & 12 & 30 & 26 & 46 \\
\hline & 5.5 & 14 & 35 & 29 & 53 \\
\hline \multirow{4}{*}{25} & 22 & 21 & 55 & 43 & 83 \\
\hline & 16.5 & 23 & 59 & 48 & 90 \\
\hline & 11 & 25 & 72 & 51 & 96 \\
\hline & 5.5 & 40 & 120 & 55 & 112 \\
\hline \multirow{4}{*}{35} & 22 & 129 & 280 & 56 & 140 \\
\hline & 16.5 & 157 & 329 & 57 & 151 \\
\hline & 11 & 200 & 404 & 58 & 163 \\
\hline & 5.5 & 301 & 561 & 59 & 174 \\
\hline \multirow{4}{*}{45} & 22 & 276 & 548 & 69 & 193 \\
\hline & 16.5 & 340 & 630 & 70 & 210 \\
\hline & 11 & 403 & 744 & 72 & 224 \\
\hline & 5.5 & 615 & 1014 & 74 & 247 \\
\hline
\end{tabular}

The fitting results of equation (1) for different types of strain values are summarized in Table 5 .

As can be noted from Table 5, the correlation coefficients for all fitting results are higher than 0.94, implying that equation (1) is practicable enough for depicting the relationship among strain values, vehicular speed, and temperature. For all types of strains, the fitted values of parameter $a_{1}$ are lower than 0 , while those of parameter $a_{3}$ exceed 0 . This further proves that strain values of asphalt layer increase with temperatures while decrease with vehicular speeds. The values of $a_{1}$ corresponding to longitudinal strains are larger than those corresponding to transverse ones, regardless of pavement types and depths.
Hence, the longitudinal strain of asphalt layer behaves more sensitive to the changing vehicular speed as compared with the transverse strain. It can also be found that the strain of semirigid pavement at $13 \mathrm{~cm}$ is more sensitive to vehicular speed than that at $24 \mathrm{~cm}$. However, the opposite trend is observed for flexible pavement: the strain at deeper asphalt layer $(30 \mathrm{~cm})$ shows higher sensitivity to speed than that at shallow position $(6 \mathrm{~cm})$.

As for the sensitivity of strain value to temperature, no apparent trend is found for the strain in the semirigid pavement. In flexible pavement, the strains at a depth of $30 \mathrm{~cm}$ are noticeably insensitive to temperature compared with those at $6 \mathrm{~cm}$. Equation (1) and the corresponding fitting results in 
TABLE 4: Strain values of asphalt layer in the semirigid pavement at different conditions.

\begin{tabular}{|c|c|c|c|c|c|}
\hline \multirow{2}{*}{ Temperature $\left({ }^{\circ} \mathrm{C}\right)$} & \multirow{2}{*}{ Speed $(\mathrm{km} / \mathrm{h})$} & \multicolumn{2}{|c|}{$13 \mathrm{~cm}$} & \multicolumn{2}{|c|}{$24 \mathrm{~cm}$} \\
\hline & & Transverse strain $(\mu \varepsilon)$ & Longitudinal strain $(\mu \varepsilon)$ & Transverse strain $(\mu \varepsilon)$ & Longitudinal strain $(\mu \varepsilon)$ \\
\hline \multirow{4}{*}{15} & 22 & 12 & 29 & 7 & 12 \\
\hline & 16.5 & 14 & 35 & 8 & 15 \\
\hline & 11 & 14 & 36 & 8 & 17 \\
\hline & 5.5 & 16 & 51 & 10 & 20 \\
\hline \multirow{4}{*}{25} & 22 & 30 & 59 & 14 & 33 \\
\hline & 16.5 & 38 & 72 & 16 & 38 \\
\hline & 11 & 41 & 87 & 20 & 45 \\
\hline & 5.5 & 48 & 104 & 23 & 51 \\
\hline \multirow{4}{*}{35} & 22 & 201 & 313 & 89 & 190 \\
\hline & 16.5 & 256 & 376 & 109 & 218 \\
\hline & 11 & 298 & 436 & 128 & 253 \\
\hline & 5.5 & 403 & 622 & 182 & 332 \\
\hline \multirow{4}{*}{45} & 22 & 387 & 630 & 161 & 367 \\
\hline & 16.5 & 475 & 886 & 184 & 438 \\
\hline & 11 & 561 & 1110 & 216 & 504 \\
\hline & 5.5 & 648 & 1318 & 262 & 613 \\
\hline
\end{tabular}

TABLE 5: The fitting results of equation (1) for different types of strain values.

\begin{tabular}{|c|c|c|c|c|c|c|}
\hline \multirow{2}{*}{ Pavement type } & \multirow{2}{*}{ Depth $(\mathrm{cm})$} & \multirow{2}{*}{ Direction } & \multicolumn{3}{|c|}{ Model parameters } & \multirow{2}{*}{$R^{2}$} \\
\hline & & & $a_{1}$ & $a_{2}$ & $a_{3}$ & \\
\hline \multirow{4}{*}{ Semirigid } & \multirow{2}{*}{13} & Transverse & -0.061 & 2.851 & 0.123 & 0.953 \\
\hline & & Longitudinal & -0.255 & 9.289 & 0.114 & 0.989 \\
\hline & \multirow{2}{*}{24} & Transverse & -0.036 & 1.932 & 0.110 & 0.941 \\
\hline & & Longitudinal & -0.083 & 3.979 & 0.114 & 0.973 \\
\hline \multirow{4}{*}{ Flexible } & \multirow{2}{*}{6} & Transverse & -0.060 & 2.723 & 0.117 & 0.961 \\
\hline & & Longitudinal & -0.151 & 7.956 & 0.106 & 0.964 \\
\hline & \multirow{2}{*}{30} & Transverse & -0.186 & 17.932 & 0.036 & 0.932 \\
\hline & & Longitudinal & -0.381 & 27.560 & 0.051 & 0.983 \\
\hline
\end{tabular}

TABLE 6: Strains of flexible pavement at different axle loads.

\begin{tabular}{|c|c|c|c|c|c|}
\hline \multirow{2}{*}{ Axle load $(\mathrm{kN})$} & \multirow{2}{*}{ Speed $(\mathrm{km} / \mathrm{h})$} & \multicolumn{2}{|c|}{$6 \mathrm{~cm}$} & \multicolumn{2}{|c|}{$30 \mathrm{~cm}$} \\
\hline & & Transverse strain $(\mu \varepsilon)$ & Longitudinal strain $(\mu \varepsilon)$ & Transverse strain $(\mu \varepsilon)$ & Longitudinal strain $(\mu \varepsilon)$ \\
\hline \multirow{4}{*}{20} & 22 & 13 & 38 & 15 & 26 \\
\hline & 16.5 & 14 & 42 & 17 & 28 \\
\hline & 11 & 16 & 50 & 20 & 31 \\
\hline & 5.5 & 21 & 62 & 22 & 36 \\
\hline \multirow{4}{*}{35} & 22 & 17 & 48 & 31 & 52 \\
\hline & 16.5 & 20 & 56 & 34 & 58 \\
\hline & 11 & 23 & 65 & 36 & 66 \\
\hline & 5.5 & 26 & 87 & 38 & 76 \\
\hline \multirow{4}{*}{60} & 22 & 21 & 57 & 54 & 97 \\
\hline & 16.5 & 25 & 66 & 58 & 106 \\
\hline & 11 & 29 & 82 & 62 & 118 \\
\hline & 5.5 & 44 & 120 & 67 & 132 \\
\hline \multirow{4}{*}{70} & 22 & 22 & 63 & 60 & 117 \\
\hline & 16.5 & 26 & 71 & 63 & 125 \\
\hline & 11 & 32 & 90 & 66 & 140 \\
\hline & 5.5 & 48 & 125 & 73 & 158 \\
\hline
\end{tabular}

Table 5 can provide references for predicting pavement strains at different temperatures and vehicular loading conditions.

The pavement strain values under FWD loading at different temperatures are presented in Figure 9.
As shown in Figure 9, similar to the strains induced by vehicular loading, the pavement strains under FWD loading are also greatly influenced by temperatures. The increasing temperature causes a rise in strain values for both types of 


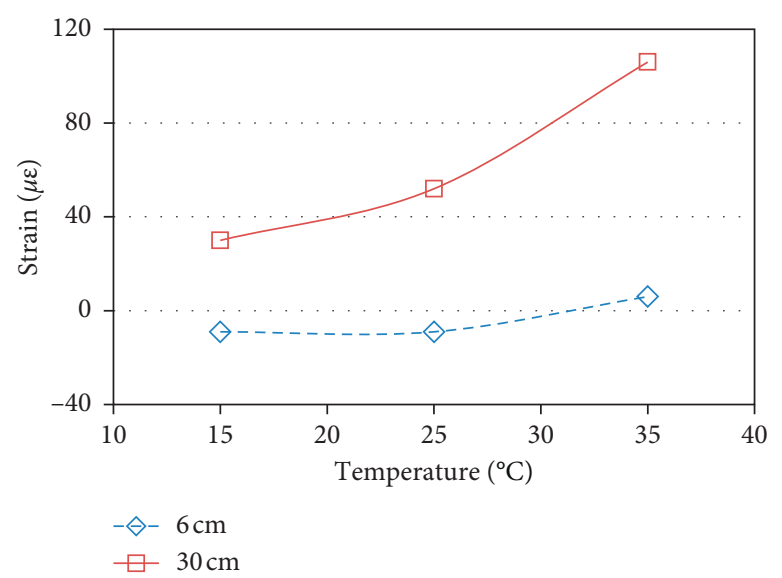

(a)

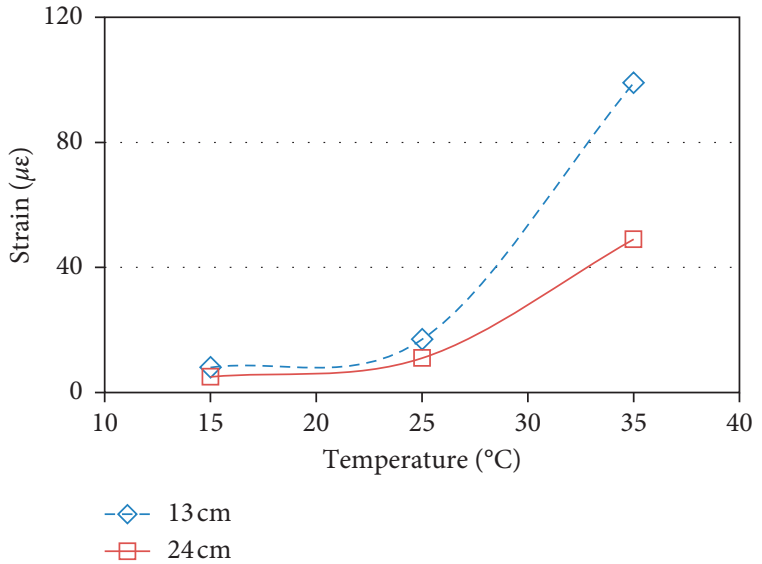

(b)

FIgURE 9: The strain values under FWD loading at different temperatures for (a) flexible pavement and (b) semirigid pavement.

pavements. The changing trend of strain values with temperatures roughly follows an exponential form.

3.4. Effect of Axle Load on Measured Strain Values. When the temperature of asphalt layer is $25^{\circ} \mathrm{C}$, different magnitudes of axle loads are applied on the pavement in vehicular loading tests. Based on the strain measurements, the effect of axle load on pavement strains is evaluated. The strains corresponding to the $50 \mathrm{kN}$ axle load have been presented in Tables 3 and 4 . The strains of flexible and semirigid pavement generated by other axle loads are shown in Table 6 and 7 , respectively.

As expected, the strain values of the asphalt layer increase with the rise of axle load irrespective of vehicular speed. When the vehicular speed is low $(5 \mathrm{~km} / \mathrm{h})$, the growing rate of strain with axle load is relatively high. As the vehicular speed turns high, the rising rate of strain value gradually slows down. To judge whether strains increase with axle loads proportionally, the rising ratios of axle load and the corresponding rising ratios of strains are compared. The comparison results for strains at different depths of two pavements are summarized in Figure 10.

As indicated in Figure 10, for most cases, the rising ratio of axle load is larger than that of strain. For the strain at $6 \mathrm{~cm}$ of flexible pavement, a contrary law is viewed. Therefore, the strain of the asphalt layer does not necessarily proportionally increase with the rise of axle load. The rising proportion of strain is generally lower than that of axle load. This may be because the contact area of the loading tire increases when the axle load rises.

3.5. Equivalent Vehicular Speed for FWD Loading. As mentioned in the aforementioned section, the strain responses of asphalt layer under vehicular loading and FWD loading can be diverse, due to the differences between two types of loadings. It is necessary to identify the relationship between pavement strain responses under FWD loading and vehicular loading. Therefore, this research compares the measured strain values of asphalt layer under two types of loadings. It is noteworthy that the shapes of strain pulses under vehicular loading and FWD loading are disparate, as seen from Figures 5-7. It is difficult to compare the strain pulses with different shapes directly. To address this issue, this research chooses the maximum tensile strains of the pulses under two types of loadings for comparison, as the tensile strain is closely related to fatigue damage within the asphalt layer. The comparison results are presented in Figure 11.

As shown in Figure 11, the strain values induced by FWD loading are always lower than those caused by vehicular loading within the speed scope of $5.5 \mathrm{~km} / \mathrm{h}-22 \mathrm{~km} / \mathrm{h}$, regardless of pavement types and temperatures. Therefore, the FWD loading represents the vehicular loading with speed at least higher than $22 \mathrm{~km} / \mathrm{h}$. At $35^{\circ} \mathrm{C}$, the deviation between strain values under vehicular and FWD loadings becomes more noticeable compared with that at $15^{\circ} \mathrm{C}$ or $25^{\circ} \mathrm{C}$.

Based on the trend shown in Figure 11, the relationship between the asphalt layer strain and vehicular speed is established. In turn, the asphalt strain under FWD loading is substituted into the strain-speed relationship, and the equivalent vehicular speed of FWD loading is back-calculated. The equivalent vehicular speeds of FWD loading for different pavements and temperatures are estimated. The estimation results are presented in Table 8.

As shown in Table 8, for semirigid pavement, the equivalent vehicular speeds of the FWD loading range between $31 \mathrm{~km} / \mathrm{h}$ and $44 \mathrm{~km} / \mathrm{h}$ at different temperatures. The equivalent speed increases with the rise of temperature. For flexible pavement, the equivalent speeds vary from $26 \mathrm{~km} / \mathrm{h}$ to $35 \mathrm{~km} / \mathrm{h}$ at different temperature conditions. However, no obvious trend is found for the relationship between equivalent speed and temperature for flexible pavement. Generally, the equivalent vehicular speed of FWD loading for flexible and semirigid pavements stays within a relatively small range as temperature changes. The average equivalent speed of FWD loading for two pavements is $35 \mathrm{~km} / \mathrm{h}$. The speed at $35 \mathrm{~km} / \mathrm{h}$ is lower than the typical vehicular speed of traffic on the 
TABle 7: Strains of semirigid pavement at different axle loads.

\begin{tabular}{|c|c|c|c|c|c|}
\hline \multirow{2}{*}{ Axle load $(\mathrm{kN})$} & \multirow{2}{*}{ Speed $(\mathrm{km} / \mathrm{h})$} & \multicolumn{2}{|c|}{$13 \mathrm{~cm}$} & \multicolumn{2}{|c|}{$24 \mathrm{~cm}$} \\
\hline & & Transverse strain $(\mu \varepsilon)$ & Longitudinal strain $(\mu \varepsilon)$ & Transverse strain $(\mu \varepsilon)$ & Longitudinal strain $(\mu \varepsilon)$ \\
\hline \multirow{4}{*}{20} & 22 & 22 & 39 & 7 & 15 \\
\hline & 16.5 & 26 & 43 & 9 & 17 \\
\hline & 11 & 32 & 51 & 10 & 20 \\
\hline & 5.5 & 40 & 65 & 15 & 27 \\
\hline \multirow{4}{*}{35} & 22 & 30 & 54 & 11 & 21 \\
\hline & 16.5 & 34 & 63 & 14 & 27 \\
\hline & 11 & 43 & 74 & 19 & 35 \\
\hline & 5.5 & 49 & 84 & 22 & 41 \\
\hline \multirow{4}{*}{60} & 22 & 41 & 76 & 15 & 38 \\
\hline & 16.5 & 45 & 87 & 19 & 47 \\
\hline & 11 & 52 & 103 & 23 & 57 \\
\hline & 5.5 & 59 & 121 & 29 & 68 \\
\hline \multirow{4}{*}{70} & 22 & 46 & 82 & 17 & 50 \\
\hline & 16.5 & 55 & 99 & 22 & 58 \\
\hline & 11 & 61 & 111 & 27 & 65 \\
\hline & 5.5 & 72 & 142 & 34 & 81 \\
\hline
\end{tabular}

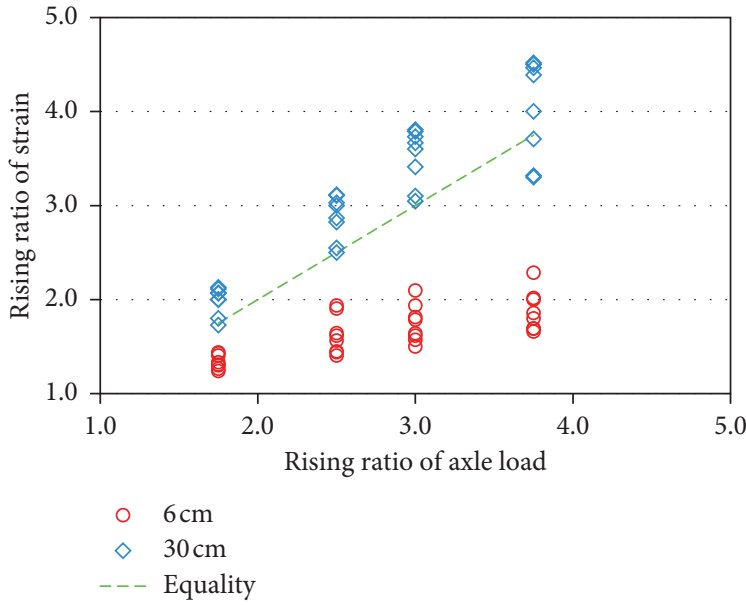

(a)

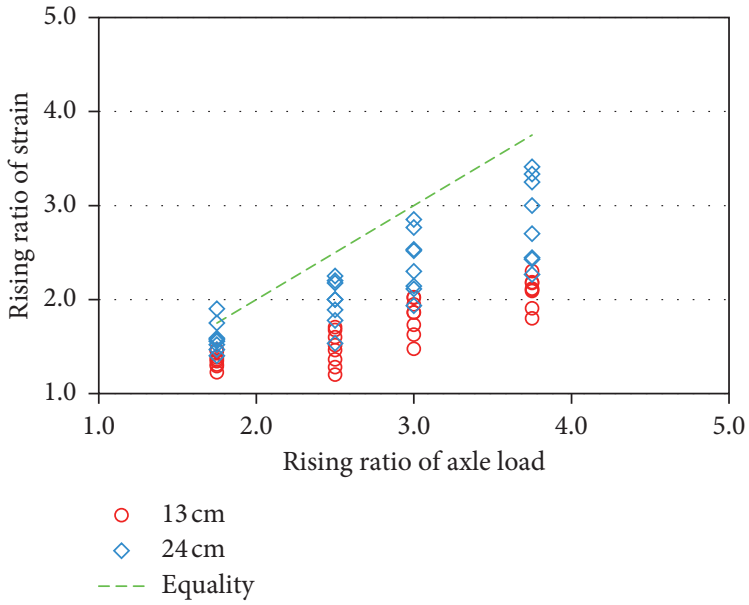

(b)

FIgURE 10: The rising ratio of axle loads vs. the rising ratio of strains for (a) flexible pavement and (b) semirigid pavement.

highway. Therefore, the measured pavement responses via FWD loading reflect the behaviors of pavement under relatively low traffic speeds. This finding may facilitate the more proper use of FWD for pavement condition evaluation.

Besides, the equivalent speeds of FWD loading obtained in this research are compared to those from other studies. The comparison results are presented in Table 9.

As shown in Table 9, the scope of the equivalent speeds from this research is rather similar to that reported by Mateos and Snyder and $\mathrm{Ai}$ et al. In addition, this scope also falls within the speed range stated by Wang and Li. By contrast, the equivalent speed recommended by Qin et al. is obviously higher than that found in this research. The above comparisons imply that the reasonable equivalent speeds of FWD loading may range between $24 \mathrm{~km} / \mathrm{h}$ and $48 \mathrm{~km} / \mathrm{h}$.

\section{Finite Element Model Simulation}

Field strain measurements only consist of a narrow scope of pavement temperatures, vehicular speeds, and asphalt layer depths, due to the limit of the loading facility or experiment cost. Therefore, the finite element (FE) models of the experimental pavements are established in this research, to simulate the strain responses of the asphalt pavement layer under a wider range of loading conditions. Both vehicular loading and FWD loading are simulated in the FE models. The FE models regarding vehicular loading and FWD loading are presented in Figure 12. The software ABAQUS is applied for developing the FE model.

The structure layers in FE models are the same as those of field pavements. In the $\mathrm{FE}$ model regarding vehicular loading, as shown in Figure 12(a), the tire-pavement contact area is modeled to shift step by step along the wheel path at a 


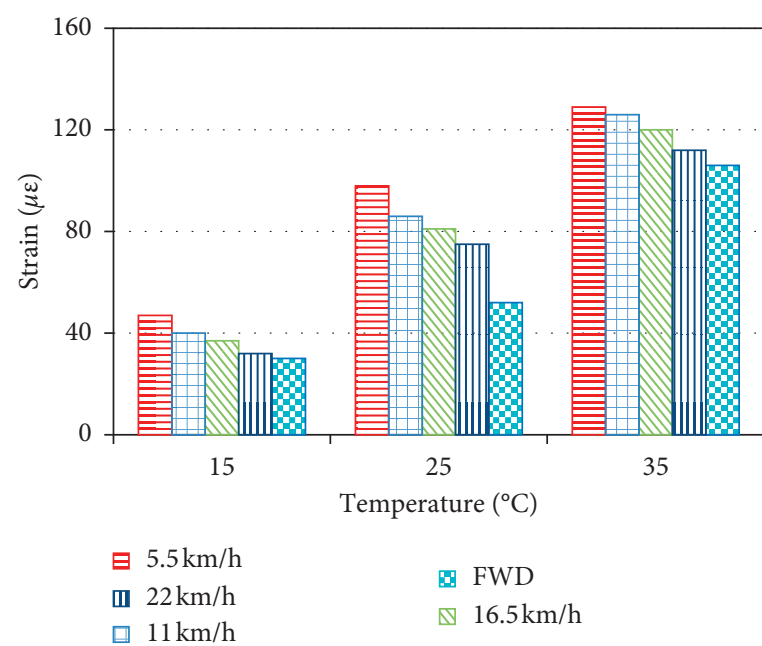

(a)

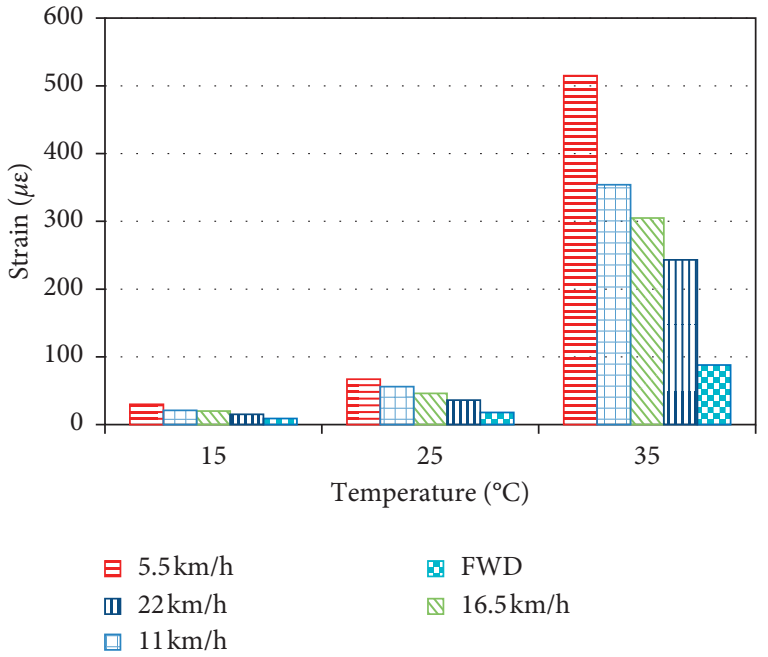

(b)

FIGURE 11: The comparisons of pavement strain values under vehicular loading and FWD loading for (a) flexible pavement and (b) semirigid pavement.

TABLE 8: The equivalent vehicular speeds of FWD loading for different pavements and temperatures.

\begin{tabular}{lcc}
\hline \multirow{2}{*}{ Temperature $\left({ }^{\circ} \mathrm{C}\right)$} & \multicolumn{2}{c}{$\begin{array}{c}\text { Equivalent vehicular speed }(\mathrm{km} / \mathrm{h}) \\
\text { Semirigid pavement }\end{array}$} \\
\hline 15 & 31 & Flexible pavement \\
25 & 38 & 33 \\
35 & 44 & 26 \\
\hline
\end{tabular}

TABLE 9: The comparisons between the equivalent speeds of FWD loading from different research.

\begin{tabular}{lc}
\hline Researchers & Equivalent vehicular speed $(\mathrm{km} / \mathrm{h})$ \\
\hline Mateos and Snyder [24] & 48 \\
Qin [25] & 88 \\
Ai et al. [26] & $26 \sim 48$ \\
Wang and Li [27] & $24 \sim 80$ \\
This research & $26-44$ \\
\hline
\end{tabular}

specific speed. The element type is C3D8I. Fine mesh is used near the loading area, while the relatively coarse mesh is used far away from the loading area. The infinite elements are used around the model to reduce the reflection of the stress wave at the boundary. In the FE model regarding FWD loading, as shown in Figure 12(b), the axisymmetric mode is used to simulate the circular loading area of the falling weight. The impact pulse loading is used. The element type is C3D8I. The mesh density decreases with the rising distance from the loading center. The infinite elements are also used around the model.

The material properties used in both types of FE models are the same. The asphalt layer is regarded as viscoelastic, while other structure layers are considered as elastic. The elastic moduli of other structure layers are back-calculated from the measured FWD deflection basins. The thicknesses, moduli, and Poisson's ratios of the modeled pavement structure layers are summarized in Table 10.

The viscoelastic behavior of the asphalt layer is defined by the Prony series expansion of the relaxation shear modulus, shown as follows:

$$
\begin{aligned}
& G(t)=G_{0}\left[1-\sum_{i=1}^{n} G_{i}\left(1-e^{-\left(t / \tau_{i}\right)}\right)\right], \\
& K(t)=K_{0}\left[1-\sum_{i=1}^{n} K_{i}\left(1-e^{-\left(t / \tau_{i}\right)}\right)\right],
\end{aligned}
$$

where $G$ is the shear modulus, $K$ is the bulk modulus, $t$ is the reduced relation time, $G_{0}$ and $K_{0}$ are instantaneous elastic moduli, $G_{i}, K_{i}$, and are Prony series parameters, and $n$ is the number of terms in the equation, which is equal to 5 in this study.

The shear modulus $G$ can be derived via the following equation:

$$
G(t)=\frac{E(t)}{2(1+\mu)},
$$

where $E$ is the relaxation modulus and is Poisson's ratio.

The dynamic moduli and phase angles of the AC- 13 mixtures used in field pavement are measured from dynamic compressive modulus test following AASHTO TP 62-03. The test data are summarized in Table 11.

Subsequently, the dynamic modulus data are converted to the relaxation modulus data based on an interconversion relationship $[23,33]$. Through the above process, the viscoelastic parameters of the asphalt mixture are obtained. The parameters corresponding to the asphalt layer temperatures in field tests are shown in Table 12 as examples.

The field measured strain data is used to validate the accuracy of the established FE model. After validation, the 


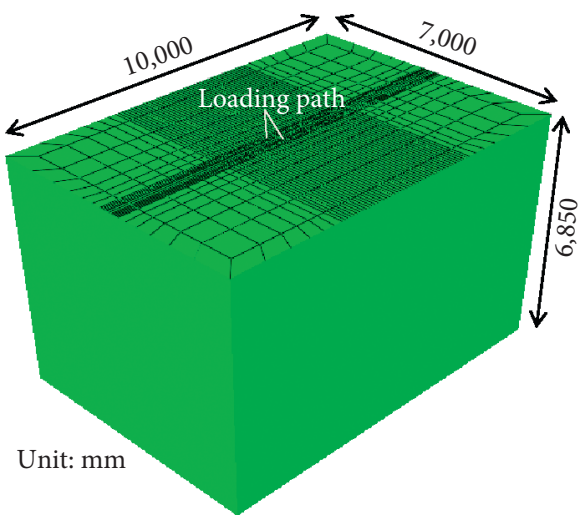

(a)

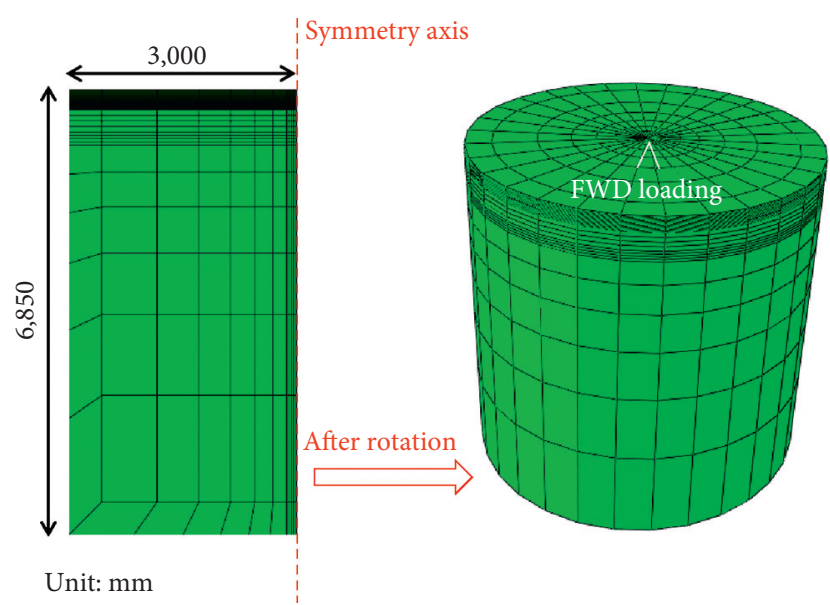

(b)

FIgURE 12: The FE models of the pavements under (a) vehicular loading and (b) FWD loading.

Table 10: The thicknesses, moduli, and Poisson's ratios of the modeled pavement structure layers.

\begin{tabular}{lcccc}
\hline Pavement type & Structure layer & Thickness $(\mathrm{m})$ & Modulus (MPa) & Poisson's ratio \\
\hline \multirow{3}{*}{ Flexible } & AC-13 mixture & 0.3 & Viscoelastic parameter & 0.35 \\
& Graded gravel & 0.35 & 435 & 557 \\
\\
& Graded gravel & 0.2 & 166 & 0.35 \\
Subgrade & 5.5 & 0.35 & 0.40 \\
Semirigid & AC-13 mixture & 0.35 & Viscoelastic parameter & 0.35 \\
& Cement-stabilized macadam & 0.2 & 38644 & 0.30 \\
& Graded gravel & 5.5 & 652 & 0.35 \\
\hline
\end{tabular}

TABLE 11: The dynamic moduli and phase angles of the AC-13 mixtures.

\begin{tabular}{|c|c|c|c|c|c|c|c|}
\hline \multirow{2}{*}{ Parameter } & \multirow{2}{*}{ Temperature $\left({ }^{\circ} \mathrm{C}\right)$} & \multicolumn{6}{|c|}{ Frequency $(\mathrm{Hz})$} \\
\hline & & 25 & 10 & 5 & 1 & 0.5 & 0.1 \\
\hline \multirow{4}{*}{ Dynamic modulus (MPa) } & -10 & 25567 & 24257 & 23113 & 20434 & 19043 & 15358 \\
\hline & 4.4 & 19677 & 17839 & 16416 & 12942 & 11562 & 8319 \\
\hline & 21.1 & 8967 & 7264 & 6155 & 3628 & 2991 & 1676 \\
\hline & 37.8 & 3248 & 2280 & 1684 & 798 & 638 & 378 \\
\hline \multirow{4}{*}{ Phase angle $\left({ }^{\circ} \mathrm{C}\right)$} & -10 & 5.95 & 6.43 & 6.99 & 8.71 & 9.70 & 12.73 \\
\hline & 4.4 & 10.58 & 11.75 & 12.91 & 16.25 & 17.81 & 22.21 \\
\hline & 21.1 & 24.03 & 26.52 & 28.24 & 32.87 & 33.97 & 36.77 \\
\hline & 37.8 & 36.64 & 34.96 & 40.23 & 41.84 & 34.76 & 32.50 \\
\hline
\end{tabular}

FE models are used to calculate the strain of the asphalt pavement layer under a wide range of loading conditions.

\section{FE Simulation Analysis}

The developed FE models in this research are used to further investigate the strain responses of the asphalt pavement layer under a broader range of loading conditions. The measured strain data is first used to validate the accuracy of the developed model. For the FE model regarding vehicular loading, the measured strain data at one intermediate temperature $\left(15^{\circ} \mathrm{C}\right)$ and one high temperature $\left(45^{\circ} \mathrm{C}\right)$ are used for validation. For the FE model regarding FWD loading, the measured data at $15^{\circ} \mathrm{C}, 15^{\circ} \mathrm{C}$, and $35^{\circ} \mathrm{C}$ are used for validation. The comparisons between the calculated and measured strains under vehicular loading and FWD loading are presented in Figure 13.

As shown in Figure 13, in general, the calculated strains can well predict the measured strains from vehicular loading and FWD loading tests. This verifies the accuracy of the developed FE models. Based on these models, the distributions of asphalt layer strains in the depth profile under a wide range of temperatures $\left(-10^{\circ} \mathrm{C} \sim 65^{\circ} \mathrm{C}\right)$ and vehicular speed $(40 \mathrm{~km} / \mathrm{h}-140 \mathrm{~km} / \mathrm{h})$ are calculated. The position of critical strain in the asphalt layer is discussed based on the calculation results. For vehicular loading, the distributions of strains within the asphalt layer at different temperatures are presented in Figure 14. In Figure 14, the vehicular speed is 
TABLE 12: Viscoelastic parameters of the asphalt mixture at different temperatures.

\begin{tabular}{|c|c|c|c|c|}
\hline Temperatures $\left({ }^{\circ} \mathrm{C}\right)$ & Instantaneous modulus (MPa) & $n$ & $G_{i} / K_{i}$ & $\tau_{i}, \mathrm{~s}$ \\
\hline \multirow{5}{*}{15} & \multirow{5}{*}{5639} & 1 & 0.3032 & 0.0001 \\
\hline & & 2 & 0.3126 & 0.0335 \\
\hline & & 3 & 0.1993 & 0.2922 \\
\hline & & 4 & 0.1079 & 2.4615 \\
\hline & & 5 & 0.0496 & 25.4584 \\
\hline \multirow{5}{*}{25} & \multirow{5}{*}{3737} & 1 & 0.4575 & 0.0001 \\
\hline & & 2 & 0.285 & 0.025 \\
\hline & & 3 & 0.1476 & 0.2038 \\
\hline & & 4 & 0.063 & 1.8502 \\
\hline & & 5 & 0.0275 & 20.2553 \\
\hline \multirow{5}{*}{35} & \multirow{5}{*}{2565} & 1 & 0.6665 & 0.0001 \\
\hline & & 2 & 0.1838 & 0.0217 \\
\hline & & 3 & 0.0818 & 0.1697 \\
\hline & & 4 & 0.0348 & 1.5165 \\
\hline & & 5 & 0.0154 & 18.1201 \\
\hline \multirow{5}{*}{45} & \multirow{5}{*}{2090} & 1 & 0.818 & 0.0001 \\
\hline & & 2 & 0.0939 & 0.0151 \\
\hline & & 3 & 0.0434 & 0.1118 \\
\hline & & 4 & 0.02 & 1.0954 \\
\hline & & 5 & 0.0089 & 16.0531 \\
\hline
\end{tabular}

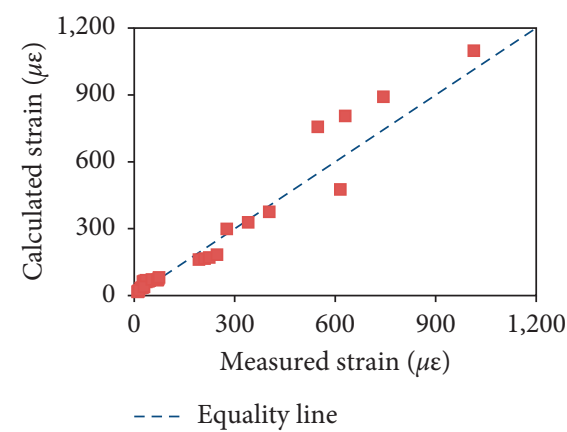

(a)

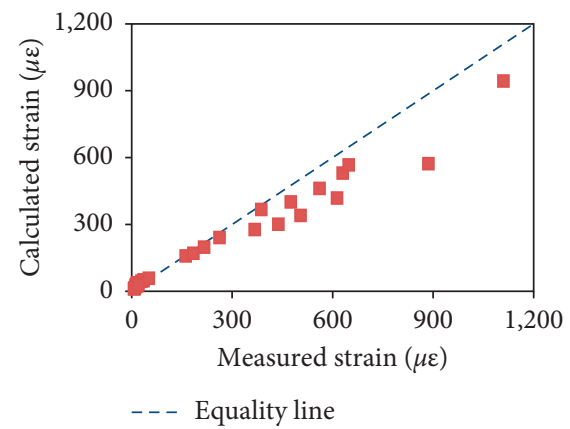

(b)

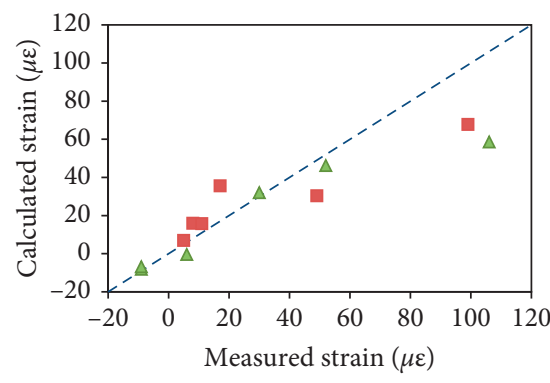

- Semirigid

$\Delta \quad$ Flexible

-.- Equality line

(c)

FIgURE 13: The comparisons between the calculated and measured strains for (a) flexible pavement under vehicular loading, (b) semirigid pavement under vehicular loading, and (c) flexible/semirigid pavements under FWD loading.

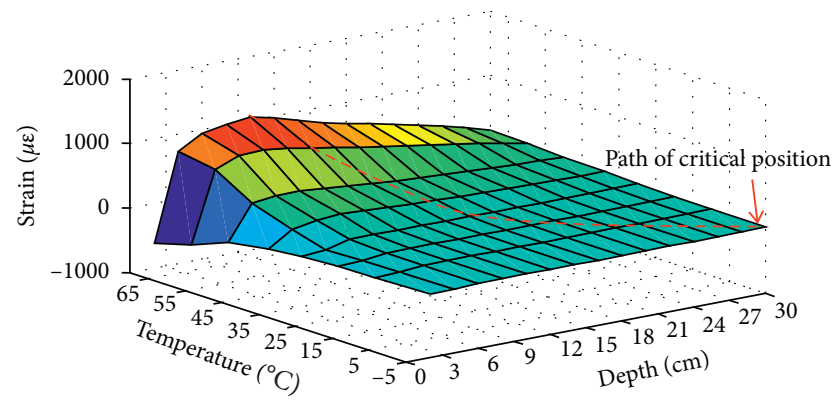

(a)

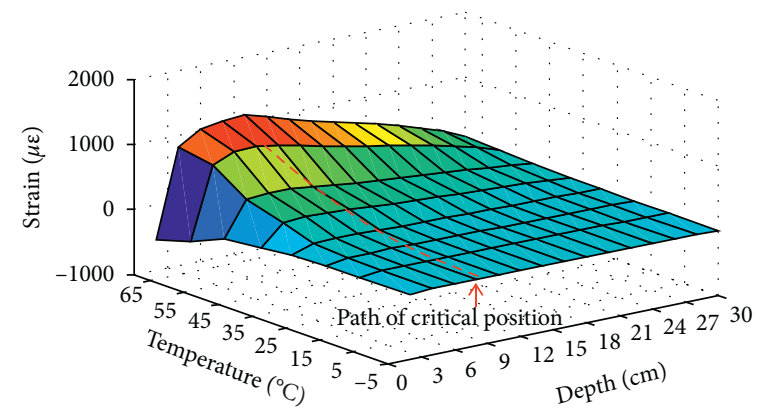

(b)

FIGURE 14: The distributions of strains within asphalt layers of (a) flexible pavement and (b) semirigid pavement under vehicular loading. 


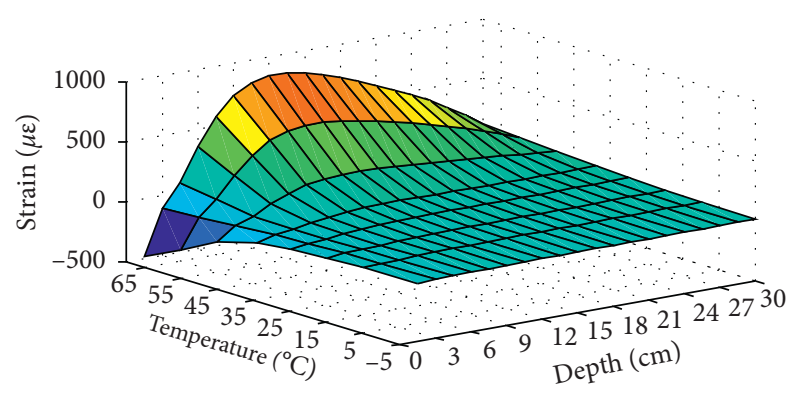

(a)

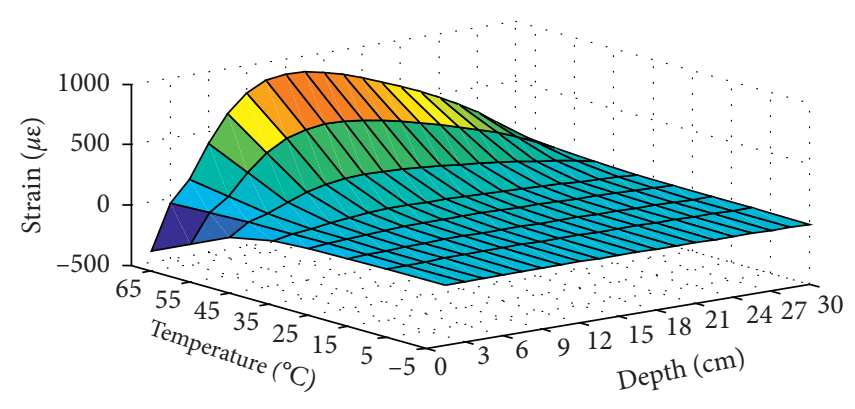

(b)

FIGURE 15: The distributions of strains within asphalt layers of (a) flexible pavement and (b) semirigid pavement under FWD loading.

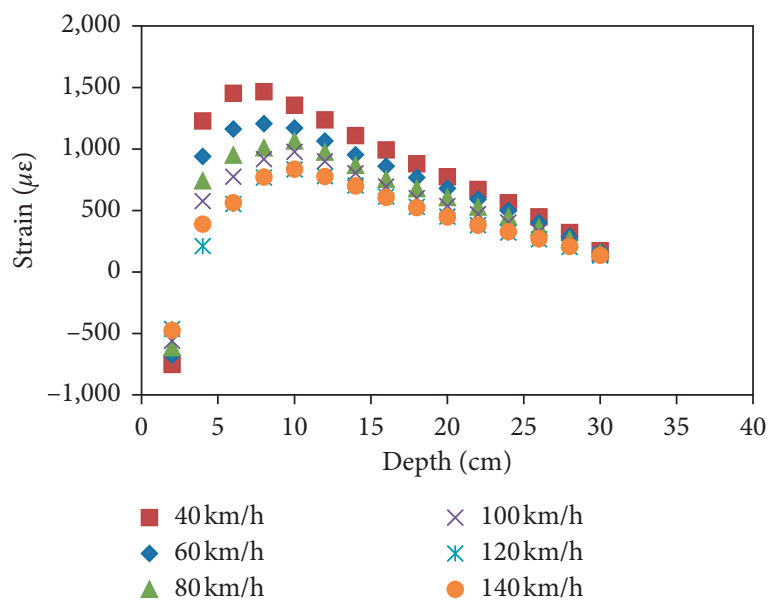

(a)

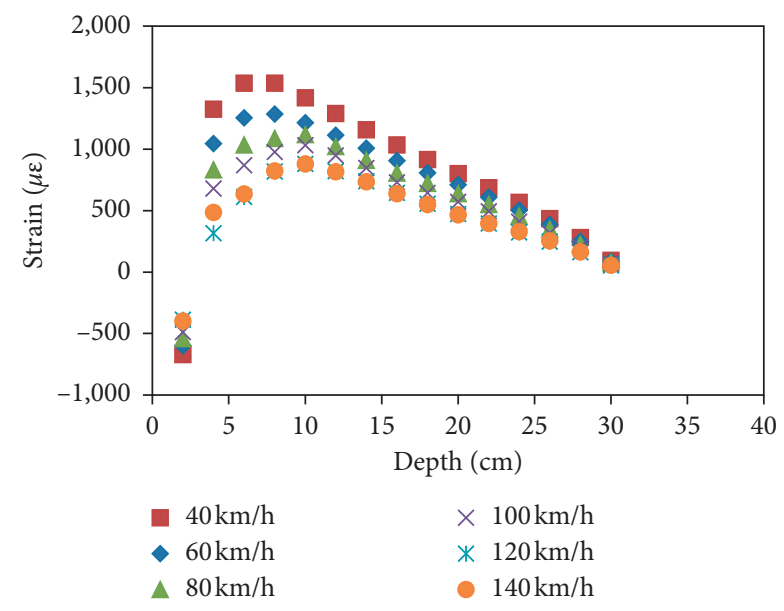

(b)

FIGURE 16: The strains of asphalt layer in (a) flexible pavement and (b) semirigid pavement at higher vehicular speeds.

$80 \mathrm{~km} / \mathrm{h}$. At other vehicular speeds, the strain distributions in the asphalt layer are similar to those shown in Figure 14.

As shown in Figure 14, for both pavements, the strains of asphalt layers increase obviously with the rising temperatures. The tensile strains of the asphalt layer at $65^{\circ} \mathrm{C}$ even exceed $1000 \mu \varepsilon$, implying that the deformations of the asphalt layer become much more predominant at high-temperature conditions. The position of critical strain in the asphalt layer refers to the depth at which the tensile strain of the asphalt layer is the maximum. The path of this critical strain position at different temperatures is also presented in Figure 14. It is noted that the critical position of the asphalt layer in the flexible pavement is dependent on temperatures. At low temperatures, this position is located at the bottom of the asphalt layer. However, as pavement temperature increases, the critical position is gradually elevated to the intermediate depth of the asphalt layer. This phenomenon indicates that the fatigue cracking in flexible pavement tends to occur at the bottom of the asphalt under low temperatures. As temperatures increase, the fatigue cracking is more likely to appear at the mid-depth of the asphalt layer. This variation of the critical fatigue positions in the flexible pavement at different temperature conditions contributes to making full use of the fatigue resistance of the asphalt mixtures at various depths.
For semirigid pavement, the critical position is always located at the intermediate depth of the asphalt layer, regardless of temperatures. As a result, fatigue cracking is most likely to appear at the mid-depth of the asphalt layer at different temperature conditions. Hence, in designing the semirigid pavement, the asphalt mixture with superior fatigue resistance ability is recommended to be used at the mid-depth of the asphalt layer.

For FWD loading, the strain distributions within the asphalt layer at different temperatures are presented in Figure 15.

As presented in Figure 15, the strains of the asphalt layer under FWD loading also increase greatly with the rise of temperatures. Besides, the critical positions of asphalt layer under FWD loading are similar to those under vehicular loading. Hence, the FWD loading is able to reflect the critical fatigue position within the asphalt layer under the real vehicular loading.

In addition, the strains of the asphalt layer at higher vehicular speeds are investigated, as shown in Figure 16. In Figure 16 , the temperature is $65^{\circ} \mathrm{C}$. At other temperatures, the varying trend of the strain with vehicular speed is similar. As presented in Figure 16, at higher vehicular speeds, the asphalt layer strains drop with the increases of vehicular 
speeds in the whole depth profile. This trend is in accordance with that reflected from field strain measurement results (as shown in Figure 8), implying that the influences of vehicular speed on the asphalt layer strain are noticeable within both low vehicular speed scope and high speed scope.

\section{Conclusions}

This research aims to investigate and compare the asphalt layer responses under vehicular and FWD loadings. Two full-scale experimental asphalt pavements are constructed and instrumented. The strain responses of field asphalt layer under vehicular and FWD loadings are measured and compared. Besides, the finite element (FE) models of the experimental pavements are established to simulate the pavement responses under a wider range of loading conditions. The calculation results from FE model are applied to analyze the position of critical strains in the pavement. The main findings are summarized as follows.

(1) For most cases, the transverse strain pulse of the asphalt layer under vehicular loading mainly contains the tensile strain zone. In contrast, the longitudinal strain pulse contains both compressive and tensile strain zones. The maximum tensile strain of a longitudinal pulse exceeds that of a transverse one. The strain pulses generated by FWD loading are different from those caused by vehicular loading. The FWD-induced pulses contain multiple peaks or valleys due to the vibration of the falling weight.

(2) The strain value of the asphalt layer increases with the temperature roughly in an exponential mode, while decreases with the vehicular speed approximately linearly. The position of critical strain in the semirigid pavement is roughly located in the middle of the asphalt layer for different temperatures. In contrast, the critical position in flexible pavement varies gradually from the asphalt layer bottom to the layer surface as temperature rises. The equation $\varepsilon=$ $\left(a_{1} \cdot V+a_{2}\right) \cdot e^{a_{3} \cdot T}$ is rather practicable for describing the relationship among strain value $(\varepsilon)$, vehicular speed $(V)$, and temperature $(T)$. Based on the above equation, the prediction models for estimating pavement strains at various temperature and loading conditions are fitted.

(3) The strain value of the asphalt layer increases with the rise of axle load irrespective of vehicular speed. The rising ratios of axle load and the corresponding rising ratios of strain are compared. The rising ratio of axle load is found to exceed that of strain for most cases, implying that the strain of the asphalt layer does not necessarily proportionally increase with the increase of axle load. Generally, the rising proportion of strain is lower than that of axle load.

(4) Within the speed scope of $5.5 \mathrm{~km} / \mathrm{h}-22 \mathrm{~km} / \mathrm{h}$, the strain values induced by FWD loading are always lower than those caused by vehicular loading. For flexible and semirigid pavements, the equivalent vehicular speeds of FWD loading range between $26 \mathrm{~km} / \mathrm{h}$ and $44 \mathrm{~km} / \mathrm{h}$, within an average speed at $35 \mathrm{~km} / \mathrm{h}$. This indicates that the measured pavement responses via FWD loading reflect the behavior of pavement under relatively low traffic speed.

(5) As indicated from the calculation results of FE models, the critical position of asphalt layer strain in the flexible pavement is dependent on the pavement temperature, while that in semirigid pavement stays unchanged as the temperature varies. The critical position of strain in flexible pavement shifts gradually from the bottom of the asphalt layer to the middepth of the layer, as temperature increases. For semirigid pavement, the critical position of strain is always located at the intermediate depth of the asphalt layer, regardless of temperatures.

\section{Data Availability}

All data, models, and codes generated or used during the study appear in the submitted article.

\section{Conflicts of Interest}

The authors declare that they have no conflicts of interest regarding the publication of this paper.

\section{Acknowledgments}

The authors acknowledge the help provided by Prof. Lijun Sun, Prof. Liping Liu, and Mr. Jiahao Li. This research was funded by the National Key R\&D Program of China (2018YFB1600100) and the Scientific Innovation Program of Shanghai Municipal Education Commission (2019-01-0700-07-E00025). The sponsorships are gratefully acknowledged.

\section{References}

[1] Y. Huang, Pavement Analysis and Design: United States Edition, Prentice-Hall, Upper Saddle River, NJ, USA, 1993.

[2] L. Sun, Structural Behavior of Asphalt Pavements, Butterworth-Heinemann, Kidlington, UK, 1st edition, 2016.

[3] C. P. Valkering and F. D. Stapel, "The shell pavement design method on a personal computer," in Proceedings of the 7th International Conference on Asphalt Pavements, Nottingham, UK, August 1992.

[4] Z. He, G. Kennepohl, Y. Cai, and R. Haas, "Development of performance models for Ontario's new mechanistic-empirical pavement design method," in Proceedings of the 8th International Conference on Asphalt Pavements, Seattle, WA, USA, August 1997.

[5] Y. R. Kim, Modeling of Asphalt Concrete, ASCE Press, Reston, VA, USA, 2008.

[6] NCHRP, Guide for Mechanistic-Empirical Design of New and Rehabilitated Pavement Structures, Final Report for Project 1-37A, Transportation Research Board, Washington, DC, USA, 2004.

[7] H. Cheng, J. Liu, L. Sun, and L. Liu, "Critical position of fatigue damage within asphalt pavement considering 
temperature and strain distribution," International Journal of Pavement Engineering, pp. 1-12, 2020.

[8] R. Belt, T. Morrison, and E. Weaver, Long-term Pavement Performance Program Falling Weight Deflectometer Maintenance Manual, Turner-Fairbank Highway Research Center, McLean, VA, USA, 2006.

[9] Y. Mehta and R. Roque, "Evaluation of FWD data for determination of layer moduli of pavements," Journal of Materials in Civil Engineering, vol. 15, no. 1, pp. 25-31, 2003.

[10] G. R. Rada, C. A. Richter, and P. Jordahl, "SHRP's layer moduli backcalculation procedure," Nondestructive Testing of Pavements and Backcalculation of Moduli, ASTM International, West Conshohocken, PA, USA, 1994.

[11] S. D. Tayabji and E. O. Lukanen, Nondestructive Testing of Pavements and Backcalculation of Moduli, ASTM, West Conshohocken, PA, USA, 2000.

[12] H. Wang, M. Li, P. Szary, and X. Hu, "Structural assessment of asphalt pavement condition using backcalculated modulus and field data," Construction and Building Materials, vol. 211, pp. 943-951, 2019.

[13] G. Zang, L. Sun, Z. Chen, and L. Li, "A nondestructive evaluation method for semi-rigid base cracking condition of asphalt pavement," Construction and Building Materials, vol. 162, pp. 892-897, 2018.

[14] H. Cheng, L. Liu, L. Sun, Y. Li, and Y. Hu, "Comparative analysis of strain-pulse-based loading frequencies for three types of asphalt pavements via field tests with moving truck axle loading," Construction and Building Materials, vol. 247, Article ID 118519, 2020.

[15] R. D. Barksdale, "Compressive stress pulse times in flexible pavements for use in dynamic testing," in Proccedings of the 50th Annual Meeting of the Highway Research Record, pp. 32-44, Washington, DC, USA, January 1971.

[16] S. F. Brown, "Determination of young's modulus for bituminous materials in pavement design," in Proccedings of the 52nd Annual Meeting of the Highway Research Record, pp. 38-49, Washington, DC, USA, January 1973.

[17] G. Garcia and M. R. Thompson, "Strain and pulse duration considerations for extended-life hot-mix asphalt pavement design," Transportation Research Record, vol. 2087, pp. 3-11, 2008.

[18] X. Hu, F. Zhou, S. Hu, and L. F. Walubita, "Proposed loading waveforms and loading time equations for mechanistic-empirical pavement design and analysis," Journal of Transportation Engineering, vol. 136, no. 6, pp. 518-527, 2010.

[19] S. Immanuel and D. H. Timm, "Measured and theoretical pressures in base and subgrade layers under dynamic truck loading," in Proceedings of the Airfield and Highway Pavements Specialty Conference, pp. 155-166, Atlanta, Georgia, May 2006.

[20] A. Loulizi, I. L. Al-Qadi, S. Lahouar, and T. E. Freeman, "Measurement of vertical compressive stress pulse in flexible pavements: representation for dynamic loading tests," Transportation Research Record: Journal of the Transportation Research Board, vol. 1816, no. 1, pp. 125-136, 2002.

[21] R. N. J. Saal and P. S. Pell, "Fatigue of bituminous road mixes," Kolloid-Zeitschrift, vol. 171, no. 1, pp. 61-71, 1960.

[22] P. S. Pell, "Fatigue characteristics of bitumen and bituminous mixes," in Proceedings of the International Conference on the Structural Design of Asphalt Pavements, pp. 43-58, Ann Arbor, MI, USA, August 1962.

[23] H. Cheng, L. Liu, and L. Sun, "Critical response analysis of steel deck pavement based on viscoelastic finite element model," International Journal of Pavement Engineering, pp. 1-12, 2019.

[24] A. Mateos and M. B. Snyder, "Validation of flexible pavement structural response models with data from the Minnesota road research project," Transportation Research Record: Journal of the Transportation Research Board, vol. 1806, no. 1, pp. 19-29, 2002.

[25] J. Qin, Predicting Flexible Pavement Structural Response Using Falling Weight Deflectometer Deflections, Ohio University, Athens, OH, USA, 2010.

[26] C. Ai, C. Xiao, J. Zeng, A. Rahmanali, and Y. Qiu, "Dynamic strain response of asphalt pavement and equivalent conversion of load effects," China Civil Engineering Journal, vol. 50, no. 1, pp. 123-132, 2017.

[27] H. Wang and M. Li, "Comparative study of asphalt pavement responses under FWD and moving vehicular loading," Journal of Transportation Engineering, vol. 142, no. 12, Article ID 04016069, 2016.

[28] JTG D 50, Specifications for Design of Highway Asphalt Pavement, China Communication Press, Beijing, China, 2017.

[29] JTG F40, Technical Specifications for Construction of Highway Asphalt Pavements, China Communication Press, Beijing, China, 2004.

[30] D. H. Timm, A. L. Priest, and T. V. Mcewen, "Design and Instrumentation of the Structural Pavement Experiment at the NCAT Test Track," NCAT Report 04-01, National Center for Asphalt Technology, Auburn, AL, USA, 2004.

[31] RIOHT, Annual Report of RIOHT Test Track-2016, RIOHT, Beijing, China, 2016.

[32] H. Cheng, L. Liu, and L. Sun, "Determination of layer modulus master curve for steel deck pavement using fieldmeasured strain data," Transportation Research Record: Journal of the Transportation Research Board, vol. 2673, no. 2, pp. 617-627, 2019.

[33] S. W. Park and R. A. Schapery, "Methods of interconversion between linear viscoelastic material functions. Part I-a numerical method based on Prony series," International Journal of Solids and Structures, vol. 36, no. 11, pp. 1653-1675, 1999. 